2018-08-13

\title{
Academics' perception of knowledge sharing in higher education
}

Annansingh, $\mathrm{F}$

http://hdl.handle.net/10026.1/13462

10.1108/IJEM-07-2016-0153

International Journal of Educational Management

Emerald

All content in PEARL is protected by copyright law. Author manuscripts are made available in accordance with publisher policies. Please cite only the published version using the details provided on the item record or document. In the absence of an open licence (e.g. Creative Commons), permissions for further reuse of content should be sought from the publisher or author. 


\section{e emeraldinsight}

\section{International Journal of Educational Management}

Academics' perception of knowledge sharing in higher education

Fenio Annansingh, Kerry E. Howell, Shaofeng Liu, Miguel Baptista Nunes,

\section{Article information:}

To cite this document:

Fenio Annansingh, Kerry E. Howell, Shaofeng Liu, Miguel Baptista Nunes, (2018) "Academics' perception of knowledge sharing in higher education", International Journal of Educational Management, Vol. 32 Issue: 6, pp.1001-1015, https://doi.org/10.1108/IJEM-07-2016-0153 Permanent link to this document:

https://doi.org/10.1108/lJEM-07-2016-0153

Downloaded on: 29 November 2018, At: 05:09 (PT)

References: this document contains references to 46 other documents.

To copy this document: permissions@emeraldinsight.com

The fulltext of this document has been downloaded 126 times since 2018*

\section{Users who downloaded this article also downloaded:}

(2018),"Knowledge sharing in higher education institutions: a systematic review", Journal of Enterprise Information Management, Vol. 31 Iss 2 pp. 226-246 <a href="https://doi.org/10.1108/ JEIM-09-2017-0129">https://doi.org/10.1108/JEIM-09-2017-0129</a>

(2018),"Tacit knowledge-sharing behavior among the academic staff: Trust, self-efficacy, motivation and Big Five personality traits embedded model", International Journal of Educational Management, Vol. 32 Iss 5 pp. 761-782 <a href="https://doi.org/10.1108/IJEM-08-2017-0193">https:// doi.org/10.1108/IJEM-08-2017-0193</a>

Access to this document was granted through an Emerald subscription provided by emeraldsrm: 614156 []

\section{For Authors}

If you would like to write for this, or any other Emerald publication, then please use our Emerald for Authors service information about how to choose which publication to write for and submission guidelines are available for all. Please visit www. emeraldinsight.com/ authors for more information.

\section{About Emerald www.emeraldinsight.com}

Emerald is a global publisher linking research and practice to the benefit of society. The company manages a portfolio of more than 290 journals and over 2,350 books and book series volumes, as well as providing an extensive range of online products and additional customer resources and services.

Emerald is both COUNTER 4 and TRANSFER compliant. The organization is a partner of the Committee on Publication Ethics (COPE) and also works with Portico and the LOCKSS initiative for digital archive preservation.

*Related content and download information correct at time of download. 


\title{
Academics' perception of knowledge sharing in higher education
}

Fenio Annansingh

Department of Business and Economics, York College, Jamaica, New York, USA

Kerry E. Howell and Shaofeng Liu

University of Plymouth, Plymouth, UK, and

Miguel Baptista Nunes

Information School, The University of Sheffield, Sheffield, UK

\begin{abstract}
Purpose - Higher education (HE) institutions create, disseminate, share and exchange knowledge through relationships among people, processes and technologies. Knowledge sharing (KS) in academia enables people within the institute to develop practices which allow them to collect and share what they know. This often leads to actions that improve services and outcomes. Despite the opportunities, this sharing is not without implications as it exposes the knowledge sharer and recipient to a number of vulnerabilities and risks, which hinders the knowledge-sharing process. The paper aims to discuss these issues.

Design/methodology/approach - This paper adopted a constructivist approach, which utilised focus group discussions within three UK universities. These were identified to improve the usefulness and effectiveness of the knowledge-sharing process.

Findings - The paper concluded by purporting that by developing an understanding of the risks and opportunities of sharing $\mathrm{HE}$, institutions will continue to grow, regenerate and develop knowledge. The results highlighted the plethora of risks and opportunities resulting from KS. These were further grouped into the political, social and organisational culture.
\end{abstract}

Originality/value - This paper addresses the gap of risks perceptions of KS in HE institutions.

Keywords Risk, Opportunity

Paper type Research paper

\section{Introduction}

The literature is inundated with the significance of knowledge management $(\mathrm{KM})$ and in particular knowledge sharing (KS) for business survival and organisational success (Rowley, 2000). KM has been promoted as a practice with implications beyond that of merely developing information and communication technology infrastructures, with information sharing and retrieval potential. In these environments, employees are actively encouraged to share knowledge and new incentives. Consequently, reward programs have been developed, not only to encourage sharing but also to facilitate the process. Knowledge has no value unless it has been shared and used (Li et al., 2014). In other words, sharing knowledge is the natural way to increase the value of knowledge. However, if $\mathrm{KS}$ strategies are not appropriately planned and by default adequately implemented, this could result in a number of implications regarding breakdown of trust, communication, cooperation and even risks.

We explored the issues of trust, risks and the implications of KS within higher education (HE) communities. As a result, we focused on the relationship between academics within the same institution as well as those externally, how KS is perceived as well as the associated risks of this practice. While the literature is inundated with discussion on KS in HE, none of these papers have addressed the issue of the associated risks implications of KS in $\mathrm{HE}$ (Wong, 2008; Holste and Fields, 2010 Trivella and Dimitrios, 2015).

Hence this paper seeks to address the perception of risks of KS, both internally and externally of $\mathrm{HE}$ institutions, as well as its impact on trust and the motivation to share knowledge.

Academics' perception of knowledge sharing \\ 1001}

Received 20 July 2016 Revised 15 November 2016 22 February 2017 1 November 2017 Accepted 2 November 2017

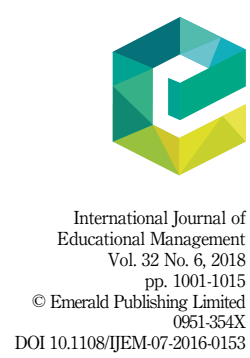


IJEM 32,6

1002

The paper begins with a thorough review of the literature as it relates to knowledge-intensive organisations within $\mathrm{HE}, \mathrm{KS}$ motives as well as risk, trust and opportunity from an $\mathrm{HE}$ perspective. This is then followed by the description of a phenomenological constructivist paradigm and ethnography as a methodological approach and the data collection method which utilises focus groups to evaluate KS practices in three universities in the UK. The approach is then followed by the data analysis, with emerging themes identified. Finally, in the concluding remarks, implications for theory and practice are explored.

\section{Knowledge-intensive organisations - HE context}

Organisational learning is always closely connected to KS (Swift and Hwang, 2013; Remedios and Boreham, 2007; Loebbecke et al., 2016). Individuals by sharing knowledge mutually achieve common understandings. Also, the effective transfer of knowledge within institutions and between people in different roles and relationships increase intangible knowledge, ideas, feedback and tangible values. According to Chua (2003) and Syysnummi and Laihonen (2014), knowledge is enriched with insights and is socially embedded in organisational practices and as such is highly difficult to imitate, trade or substitute. Consequently, KS is an effective strategy in building up competitive advantages for all types of organisations (Remedios and Boreham, 2007; Aminbeidokhti et al., 2016). Furthermore, Riege notes that competitive advantage is based on effectively sharing knowledge as a key component of KM programme. Universities, therefore, based on the characteristics offered by Alvesson (1995), can be classified as knowledge intensive, which are characterised by:

- significant incidents of problem solving;

- creativity from the practitioner and the organisational environment;

- heavy reliance on individuals and a high degree of independence;

- high educational levels and professionalisation; and

- critical information is in the mind of employees, networks, customer relationships, manuals and systems for supplying services.

Universities not only serve as research, teaching and learning institutions, but they are also in the business of generating, disseminating and sharing knowledge. As the world changes into a knowledge society, $\mathrm{HE}$ is also changing and adapting to this new reality in which knowledge is acquired not only traditionally via curriculum-based face-to-face courses but through a combination of novel channels (Forkosh-Baruch and Hershkovitz, 2012; Aminbeidokhti et al., 2016; Trivella and Dimitrios, 2015). Effective KS is vital for universities to distinguish themselves from other institutions, as well as to gain or maintain their competitive advantage (Rowley, 2000). This discovery has led to the implementation of systems and mechanisms that enable the retention and exploration of knowledge developed over time by key personnel, as well as the need to develop and establish methods which allow for KS (Al-Busaidi and Olfman, 2017).

In HE, this is particularly evident in studies by Li et al. (2014), Cranfield and Taylor (2008), Fullwood et al. (2013) and Aminbeidokhti et al. (2016) which highlighted the usage of KM tools such as web-based portals, knowledge repositories such as e-libraries, e-learning as well as the convergence of e-business applications. The acquisition and usage of these tools not only contribute to the organisational knowledge assets but must be harnessed in order to exploit emerging opportunities. However, the motivation to share knowledge can prove challenging even for organisations where such practices are actively encouraged and rewarded. Consequently, the next section discusses motivation for KS in knowledgeintensive organisations such as universities. 
Motivation for knowledge sharing in $\mathrm{HE}$

Knowledge needs to be shared and distributed with clear awareness of the purpose, use and the potential beneficiary from the sharing processes (Ford and Staples, 2010; Aminbeidokhti et al., 2016). According to Al-Busaidi and Olfman (2017), although it is somewhat difficult to extract expertise and learning from one person and transfer it to another, the alternative is to lose knowledge gained through experience, training and teamwork. Without the sharing of knowledge, organisations would continuously reinvent themselves and there would be no way of leveraging experience and expertise. In $\mathrm{HE}$, it is the crucial assumption that academics might gain knowledge from the experiences and expertise of their peers. Organisations that share knowledge increase the opportunities for the creation of new ideas that have the potential of adding value to their activities. Failure to manage and share knowledge could prevent the creation and distribution of knowledge. Therefore, critical to the HE process is the need to effectively exploit their intellectual and social capital gained through research and experience Syysnummi and Laihonen (2014). Social capital is the formation of strong networks and personal relationships between individuals or groups that provide the basis for trust, communication, cooperation and collaboration. Intellectual capital, on the other hand, refers to knowledge and the knowing capability of an organisation or community of practice (Nahapiet and Ghoshal, 1998). Even though academics are active creators of knowledge (intellectual capital), it is nonetheless challenging for HE institutions to get faculty to share through networks. Consequently, knowledge exists today in these institutions as separated and in knowledge silos.

Since the value of knowledge increases during the process of KS, people are more likely to hoard it unless there are strong personal motivations to do otherwise (Loebbecke et al., 2016; Ford and Staples, 2010). Therefore, motivational issues become vital in building successful KS activities in $\mathrm{HE}$ where academics feel that they are competing for the same limited resource. Hsu and Chang, (2014) also indicated that once individuals share knowledge, they may lose the ownership of the knowledge and the benefits thereof.

Motivational factors become essential, and these can be categorised into internal and external factors (Ipe, 2003). Internal factors include the power that resides in knowledge assets and reciprocity resulting from sharing. External factors include relationship with the recipient and rewards. Knowledge as power becomes a dominant motivator for sharing knowledge and indicates that in the organisation, individuals who possess right kind of knowledge are helpful to generate the notion of power derived from knowledge. In HE, knowledge is often generated through research and the recognition derived from the number of prestigious publications and the income generated from external funding bodies. Hence, individuals lower down the organisational hierarchy and with less power are more likely to pass knowledge to those individuals with higher status and more power. However, those with higher status and power are more likely to share their knowledge with others of similar status and power, rather than people with lower status and less power (Ipe, 2003).

Some people may expect sharing knowledge will earn them a good reputation and improve their status within their social group (Cabrera and Cabrera, 2002) especially in academia where status is determined by the quality of knowledge shared externally. Reciprocity, however, only facilitates KS when individuals perceive that the benefits received depend on the extent to which they share their knowledge with others (Ipe, 2003; Syysnummi and Laihonen, 2014). Therefore, the reciprocity relationship is essential for effective KS and rather fundamental for successful KS project building. Additionally, the relationship with recipient has a significant influence on the motivation to share knowledge (Ford and Staples, 2010). This is often based on trust, as well as the power and the status of the recipient.

Like organisations, $\mathrm{HE}$ institution groups and individuals are forced to both compete and cooperate with each other. These groups/individuals are expected to learn and benefit from new knowledge developed by their colleagues while competing against each other for
Academics' perception of knowledge sharing

1003 
IJEM

32,6

1004

internal resources and competencies, rewards, status and external recognition. This creates dialectic thinking, as there is a need to balance between sharing too much and too little knowledge, as KS becomes a demanding and uncertain process (Trkman and Desouza, 2011; Williams and Jacobs, 2004). At the individual level, the request to share knowledge may evoke perceptions of conflict of interest or vulnerability (Matzler et al., 2008). Thus, for knowledge-intensive $\mathrm{HE}$ institutions, with complex and evolving structure, KS may diminish the individual's motivation to share (Matzler et al., 2008) and increase the risks and uncertainty of sharing knowledge. As a result, the proceeding section discusses the concept of trust as it relates to risks and opportunities arising from KS.

\section{Risk, trust and opportunity associated with knowledge sharing}

KS can lead to knowledge creation (Barker, 2015). However, individuals sometimes hesitate in sharing knowledge especially when there is risk that this could be exploited by someone else (Ford and Staples, 2010). Indeed, if organisational knowledge is a valuable asset/ resource (Connelly et al., 2011; Williams and Jacobs, 2004), it needs to be protected as well as exploited for business and competitive advantage. Effective risk identification and management procedure need to be considered and implemented to protect this asset as with any other organisational asset (Rowley, 2000). However, KS risks are not quantifiable as they are not associated with easily interpreted data. These risks are highly subjective and depend on the perception of the decision maker. Consequently, KS risks will be labelled differently and the perception of their impact widely dispersed (Trkman and Desouza, 2011; Sadiq Sohail and Daud, 2009).

There are two inherently different approaches to manage risk, reactive and proactive approach. Reactive risks approach does not fulfil the requirements of surviving in today's competitive environment and is considered passive and waiting. Proactive risk management (Alberts and Dorofee, 2010; Kliem and Ludin, 2000) can be broken down into a number of steps and is represented by an adapted version of the risk management framework seen in Figure 1. This paper considers the execution of the risk management activities which can be broken down into a number of steps, namely risk assessment and risk control. Particular emphasis is on the risk assessment process which involves risk identification and thus seeks to ascertain the KS risks in $\mathrm{HE}$.

Therefore, owing to the risks of loss arising from the KS process, trust between parties is crucial (Schoorman et al., 2007). Trust, in fact, has been considered as a prerequisite for KS (Ghobadi and Mathiassen, 2016; Schoorman et al., 2007). Without trust individuals would safeguard, hoard or hide their knowledge without the desire to share even when they are encouraged and rewarded to do so (Connelly et al., 2011; Hsu and Chang, 2014; Sadiq Sohail and Daud, 2009). The level of trust between individuals and teams will be influenced by the

Figure 1. Adapted risk management framework

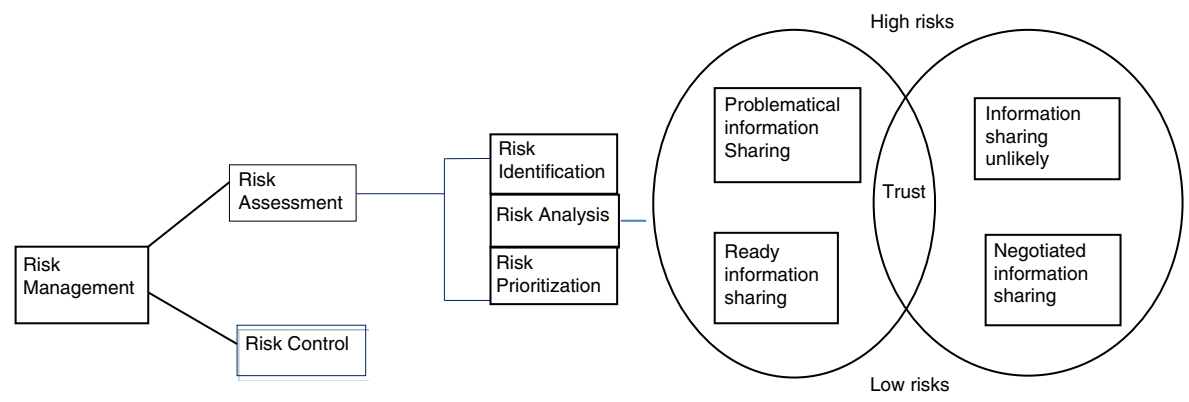

Sources: Alberts and Dorofee (2010) and Kliem (2000) 
nature of the organisational structure, culture and the degree of benefits returned. Trust influences the level of risk and uncertainty arising from the KS process within organisations and external environment. The KS process gives rise to a high level of risk and uncertainty which can be reduced by high level of trust (Ghobadi and Mathiassen, 2016; Holste and Fields, 2010; Loebbecke et al., 2016). Therefore, KS involves uncertainty and risk, but the amount and kind of risk vary depending on the type of exchange. In reciprocal exchanges, the knowledge sharer risks giving information unilaterally while receiving little or no returns. Hence, a demonstration of trust is required. Negotiated exchanges of KS are also associated with risks especially when determining the terms of sharing as these may be unequal and unsatisfactory to one or both parties (Barker, 2015).

Trust and risk are intrinsically linked; individuals who give trust to others do not continually monitor the activities of those they trust. Without trust what matters to me would be unsafe (Baier, 1986). Human activity is oriented towards future outcomes. In many respects, the future is uncertain and involves risk. Uncertainty and risks involved here include the contingent actions of others (individuals, groups or institutions). As humans, we can never be sure how those we interact with will act at any moment in reaction to our activities. Indeed, the success or failure of anything we wish to undertake is determined by the reactions of others. That said even though uncertainty and risk exist, activity is required to satisfy and realise needs and objectives. Consequently, human beings are required to gamble on the future uncertainty relating to the actions of others. When we gamble regarding how others will react or act in certain situations, we deploy a notion of trust.

Individuals and institutions usually act in a rational manner and calculations regarding actions will be based on such variables. Activities that involve the investment of trust towards others are based on estimations of trustworthiness and the extent people will act as rational agents or as they have acted in the past. We consider that an individual's reputation, past performance or appearance determines the extent that the subject will trust others; knowledge of those to be trusted will have an impact on the extent to which subject will trust them. Even though trust involves an understanding and dissection of complex logic incorporated in rational estimates the level of trust individuals are willing to deploy, and the amount of risk they are ready to take on are not exclusively dependent on the qualities of another person. They also depend on our subjective predilections to trust in relation to objective judgments regarding that to be trusted. In this paper, we explore the extent to which individual researchers rely on colleagues and institutions when deliberating the extent they trust others with their ideas regarding joint research and KS. Risks regarding KS were investigated, and levels of trust concerning such dilemmas were ascertained. Such an investigation required a phenomenological constructivist paradigm of inquiry deployed through ethnography and focus groups.

\section{Paradigm of inquiry and methodology}

This research adopts a phenomenological constructivist paradigm and ethnography as a methodological approach. It focuses on an understanding of the social world from the level of subjective experience. Based on the phenomenological perspectives, the constructivist ethnographic approach considers human understanding to be subjective and relative. "Ethnographic studies [...] provide social scientific descriptions of people and their cultural bases; in such a way we can develop comprehensions of 'self' in relation to 'other' in terms of becoming" (Howell, 2013, p. 129). A constructivist ethnographic study develops an integrated synthesis of theory and practice. Indeed the "final interpretative theory is multivoiced and dialogical. It builds on native interpretations and articulates what is implicit in those interpretations" (Denzin and Lincoln, 1994, p. 120). "Experience is intersubjective and embodies not individual and fixed, but social and processual. Intersubjectivity and dialogue involve situations where bodies marked by social [...] that is, by difference $[. .$.$] may be$
Academics' perception of knowledge sharing

1005 
IJEM 32,6

1006

presented as partial identities" (Tedlock, 2000, p. 471). The constructivist ontological perspective and epistemological stance are concerned with relativist realism and the users' understanding of reality. It sees the social world as a social process that is continuously developing and evolving and consists of a network of assumptions and shared meanings. The phenomenological constructivist paradigm seeks to understand the perceptions and perspectives of the people who are involved in the KS and transfer activities in the organisation. From an ontological perspective, constructivist ethnographer researchers view the social world as highly complex and problematic, where everyday life is an incredible achievement. The constructivist ethnographer seeks to interpret, understand, experience or produce the very basis and source of social reality (Cranfield and Taylor, 2008; Wong, 2008). Based on these arguments and the need to extract the perceptions and perspectives of participants, in this research a constructivist ethnographic stance was appropriate (Cranfield and Taylor, 2008; Wong, 2008).

\section{Data collection-focus group discussion}

This research adopts a qualitative approach using focus group discussions (FGDs). Qualitative research, unlike the natural sciences, is concerned about people and their social reality. Therefore, any attempt to understand social reality must be grounded in people's experiences and perceptions of that social reality. This reality has already been interpreted by the individual. Thus, the investigator must understand the motivation behind an individual's interpretation of the situation, which leads to their action (Bryman, 2015). Failure of the observer to recognise, capture and interpret these meaningful experiences runs the risk of losing touch with the reality and therefore depicting a fictional world, existing only in the mind of the observer.

Focus groups were selected as the means for the data collection as they allow access to individual opinions and they intensify the opportunity for the participants to decide the direction of the research. FGDs are particularly useful when there are power differences between the participants when the everyday use of language and culture of particular groups is of interest, and when one wants to explore the degree of consensus on a given topic (Morgan and Kreuger, 1993). For this study, it was essential to obtain a consensus on the perception of risks in KS. They minimised the control of the researcher and provided an environment that encouraged plurality in the construction of knowledge. Focus groups are an effective method of producing concentrated amounts of data on the topic of interest. They provide synergy of data which according to Morgan (1997) makes them superior to interviews as the interaction between the participants provides more significant insights into their opinions and experiences (Morgan, 1997). Since the intent of FGDs is self-disclosure, precedence was given to participants and what they considered significant. This meant building collective understanding through individuals in the group asking questions and challenging one another. Participants entered conversations and group interaction that accentuated empathy and commonality regarding shared experiences, perceptions and perspectives. This encouraged self-disclosure, self-understanding and selfvalidation. Communication allowed the participants to build on each other's thoughts and opinions and provided evidence that individual opinions are valid and legitimate.

The FGDs were used to explore a specific set of issues with the discussions focusing on sets of questions regarding KS, and the perceived risk, if any, associated with this practice. They were used to explore individual experiences opinions and concerns. We attempted to ensure multiple lines of communication which allowed for people to share ideas, beliefs and attitudes (in the case of this research) from similar professional backgrounds. In this context, homogeneity can be productive whereas heterogeneity can provide some insight. However, the total control of participant characteristics in many instances was unrealistic. There are a number of limitations to focus groups which include the tendency for certain 
types of socially acceptable opinion to emerge, as well as for specific participants to dominate the discussion. Nonetheless, there are ways of setting up and moderating the groups which may reduce these limitations (Smithson, 2000). Consequently, the FGDs encompassed colleagues from three universities; two research-intensive universities (FGA and FGC) and one post-1992 (FGB), all were videotaped and then transcribed.

FGA was undertaken in a red brick university which was initially formed by the merger of three colleges in 1897. It is one of the six red brick universities and consistently seen as one of the top 20 colleges in the UK. FGC is a member of the 1994 Group of research-led British universities. In the latest Research Assessment Exercise in 2014, two-thirds of FGC individual subject submissions were ranked in the top 10 nationally, with over a third in the top 5 . The roots of FGB can be traced back to 1825 and from 1880 until 1970 delivered degrees from the University of London. In 1970, it became a Polytechnic and a University in 1992. FGA and FGC traditionally delivered medicine, arts and science and FGB initially mechanics but by the mid-nineteenth century arts and science were also central to the emerging college. The main difference emerged when FGA and FGC were given a Royal Charter in 1905 and 1966, respectively, whereas the latter continued to deliver degrees researched and developed by another institution until the 1970s. One may consider this a significant change in pathdependency for the former institutions and the basis of the development of a research-led disposition. As the latter simply delivered the material from another institution, the impetus for research may have been nullified. The question is to what extent has this impacted on individual perception regarding risks of KS? The focus groups were set up to investigate differentiations in attitudes towards KS in these institutions.

FGA and FGB involved 13 participants each, while FGC had 9 individuals and all interviews were videotaped and transcribed. The participants consisted of academic staff at different career stages; these included, professors, readers, senior lecturers, early career lecturers and research fellows/assistant. These individuals were selected as the researcher believed that they had intimate knowledge of the various institutions and represented a broad cross-section of the population. The research design focused on KS relating to teaching and research, sharing of best practices and lessons learned which all have incentives and rewards for KS. The discussion of the paper is limited to KS as it relates to research and teaching does not consider administrative functions.

\section{Data analysis}

Each focus group generated massive amounts of rich, dynamic data. However, such richness and dynamism made the data challenging to manage. Consequently, data analysis was done by referencing the group context (this means starting with the group rather than the individual). Data analysis relied on aspects of grounded theory and through open and selective coding procedures developed categories (sustainability, creativity and innovation) that eventually identified core categories relating to risk and trust. General terms were identified in the data relating to trust, risk and opportunity; the associated risks of KS were then coded in relation to the emerging data. Analysis involved remaining "open and close" to the emerging data through "simple, precise coding" and comparative analysis. According to Charmaz (2010), coding requires us to ask analytical questions (and) study fragments of data - words, lines, segments and incidents - closely. Data analysis was systematic, sequential, verifiable and continuous (Krueger and Casey, 2000). This provided a balance between the perspective of the groups as a whole and the recognition of the individual participants. Distinction was made between the opinions expressed in spite of the group and those in opposition to the group as well as occasions when consensus and compromise were expressed and constructed by the group.

The objective of the study was to enable trustworthiness and validity regarding individual perceptions of the relationships between academics when developing and sharing knowledge.
Academics' perception of knowledge sharing

1007 
IJEM

32,6

1008

Therefore, rather than identifying reliability and replication which can be extremely difficult in phenomenological constructivist research, the methodological approach pursued experiential validity and the extent the real-life situations can be represented.

The next section of this paper outlines the themes in more detail and identifies how they emerged from the categories to provide conceptualisations and interpretations of different perspectives of sharing and associated risks. During the analysis process, categories emerged from the data about notes and memos kept during the data collection process. These were incorporated into trust, opportunities and the associated risks of KS.

\section{Description of findings}

Trust - risk or opportunity

KS occurs between one who is in possession of knowledge and the other who requests this knowledge. Trust is based on honesty, integrity and reliability as well as confidence in a person or institution. Without trust of colleagues, institutional processes, procedures and systems that implement KM, knowledge will not be shared. Trust in $\mathrm{HE}$, therefore, is necessary for the dissemination and transfer of knowledge as it forms the basis on which academic communities function and thrives. It is based on trust, integrity and professionalism that any academic would discuss their ideas with colleagues or submit an article for review and scrutiny by independent parties. However, while trust is established as a necessity for KS, even within academic environments individuals are often not as open with their knowledge, as would be expected, because they are also in competition:

[...]I have been slightly guarded with people following meeting [...] if they're asking me about very specific things, I'll be thinking what are they going to do with that if I tell them exactly my view. $[\ldots]$ are they then going to publish it and become this nice sort of de facto definition? (FGC).

Therefore, interactions between the groups require trust, either concerning the integrity and motive of the knowledge sharer or the recipient.

Regardless of culture and historical background, HE institutions value their ability to disseminate and share knowledge. However, the motivation for sharing knowledge at times can be lacking depending on the organisation and the individuals. Even though internal KS between colleagues is expected and is part of the job remit, some within FGB were reluctant to participate in these activities. This resulted in a division among the focus groups regarding trusting colleagues to share knowledge. Participants of FGB found trusting of one's colleagues to share knowledge more difficult than sharing externally. This lack of trust was evident and was based on participants fearing knowledge loss, power and competitive advantage. This point of view was expressed in FGB where participants acknowledged:

$[\ldots]$ it's their intellectual property, they own it, and they don't want to share it with anyone else because it empowers them (FGB).

The environment in FGB was also seen as highly political and bureaucratic, which tends to foster competition rather than cooperation and collaboration. Consequently, individuals actively involved in research were only willing to share knowledge with colleagues when it was at the point of publication as seen in the following statement:

$[\ldots]$ there's some research which you want to keep until you are going to publish the outcome of the research, before you can plan to share with these people (FGB).

In FGA there was a higher level of trust as internally participants were willing to share knowledge with colleagues. Since KS is based on shared interest, openness and clear communication between colleagues were often encouraged and essentially fostered in the formation of research groups, seminars and discussion forums. As such, KS was highly 
valued and seen as an efficient mechanism to achieve clarity, new knowledge, career enhancement, idea refinement, support and development. This was supported by a participant in FGC who claimed:

[...] if I want a second opinion on something, I might then go and chat about some aspect of my work [...] because the point you need to work through your ideas openly prior to publication [...] we ask each other's opinions (FGC).

With such openness and cooperation, it would not only be difficult but also unacceptable for work colleagues to misappropriate ideas from each other. This level of trust was also manifested in FGA:

But you might share it more with people here, because people here know what you're doing, and you cannot just easily steal it from them (FGA).

Additionally, any breach of trust could lead to conflict and a breakdown in communication as well as any collaborative effort. Trust in this sense is not wholeheartedly utopian, as participants were aware that there are risks, both internally and externally, in KS. Externally, there was a resigned acceptance of the risks of $\mathrm{KS}$, as it was seen as a required part of scholarly activities as well as a route for career progression:

But as an academic there's rarely any benefit to your career through refusing to publish (FGA).

Indeed, KS becomes a double-edged sword which can either be exploited as an opportunity or mitigated as a risk. Even though establishing external networks was seen as an ideal foundation for developing contacts and a robust research profile, participants in both FGA and FGC were aware that at times this could become political and as such caution should have to be exercised when sharing newly developed and unexplored ideas with external parties as they are competitors. There is also a heightened chance that outside the institution research areas and ideas may overlap. This could prove challenging as institutions and individuals are competing for the same limited resource as well as the drive to mark their intellectual territory. Nonetheless, despite the obvious risks, participants were willing to continue KS activities externally and thought it unprecedented not to continue with such traditions. Prominence is given to external KS within the academic arena because of potential for recognition and promotion for the sharers. In FGB and FGC, this was also seen as an opportunity to expand network outside of their institution socially. Hence, from the FGDs networking, both internally and externally, is vital for academics as seen by the remarks in FGB and FGC:

$[\ldots]$ is hugely valuable. Not just from the point of view of publishing but for jobs in the future. The bigger your network, the more mobile you are (FGB).

[...] outside the organisation I share knowledge almost exclusively by presenting work at conferences or publishing [...] So there is a kind of international sort of community of practice [...] [which] spark possible collaborations (FGC).

While it was agreed that there could be breach of trust by some individuals, there is the general belief that the current framework provides adequate protection from theft and abuse. Having too much structure could become a deterrent to the KS process. This view was shared by participants in FGA who stated that:

If you try putting too much structured in place there is the risk that you will lose knowing the benefits of the fluidity that are present in the current system (FGA).

Therefore, finding the right balance is imperative to encourage $\mathrm{KS}$ and building the knowledge base of the institution. This, however, will be influenced by the organisational culture and the commitment of staff and management to the process.
Academics' perception of knowledge sharing 
IJEM 32,6

Trust is somewhat unnatural in a highly competitive and risky environment, as the natural instinct of most people is to protect their intellectual property. However, refraining from this can thwart knowledge development, generation and sharing. Consequently, academics remain tentative to whom, when and where they share knowledge. Nonetheless, KS presents opportunities which, if exploited, could lead to knowledge generation and refinement, innovation and career progression but it also constitutes risks, which may paradoxically prevent the realisation of some of these benefits.

\section{Knowledge sharing risks}

As we have just discussed, KS is based on trust; however, establishing and maintaining trust within a competitive environment such as $\mathrm{HE}$ is not always easy. This is because of the associated risks of KS which have been identified and accepted by the FGDs. Depending on the parties involved in the KS process, the level of perceive risks will either increase or decrease as well as the willingness to share. Practices of such nature were expressed by members of FGB and FGC who believed:

$[\ldots]$ the type of knowledge would actually influence the way we share knowledge (FGB).

[...] $90 \%$ of the stuff I do, I do with the four guys in my office. This isn't a manifestation of a culture - but the dynamics of a small group that happens to work. It's born out of friendship (FGC).

Even though there are associated risks with any KS activity, the divulger's willingness or reluctance to share often depends on the level of knowledge required and their status within a group or society. The less threatening or the lower the status of the recipient the more willing the sharer would be to disclose or part with their knowledge. For example, lecturers have no problem sharing knowledge with students as they see the risks of doing so are minimal or performance based. However, KS between peers and colleagues and the associated risks is dependent on the organisation culture and how KS is viewed among staff. Cooperation between colleagues is seen as an opportunity to reduce the probability of risks between staff and promote greater opportunity for collaboration and networking. This was further substantiated in FGA, participants mentioned that:

$[\ldots]$ if there is actually trust there between them, they would not actually have any risks and challenges if they cooperate with each other (FGA).

Likewise, participants believe the more significant the competition within the organisation the higher the likelihood of risk arising. Competition, however, tends to be greater outside the organisation rather than internally as there are greater areas of overlap in the body of knowledge which could result in knowledge leakage (KL) and theft. This risk of KL occurs internally and externally during KS processes and activities. An example of which was seen in FGC:

I recently had an experience of my work being ripped off by somebody else and pinched prior to publication, which was quite frustrating. So I guess that is a risk $[\ldots]$ inadvertent KS (FGC).

KL risks also increase with the status of the sharer and recipient, as well as the rapidity and expediency in disseminating knowledge to the audience. Being the originator of a particular idea offers academic accolade within a particular community. Therefore, being the first to present and build on this idea offers status and power. Participants believe that this was mainly relevant and onerous to students and researchers who often rely on their supervisors to provide honest and constructive feedback to their research without fear of their ideas being misappropriated or unfairly disclosed. Recognition of one's contribution, whether written or verbally, to the knowledge development or generation process was also crucial for 
symbiotic associations. Here recognition and acknowledgement is seen as a reward for having shared knowledge. This was evident in FGC:

I think there would be an implicit understanding that if you provide significant input you'll be recognised for it. They wouldn't just take that idea and pass it off as completely their own, there would be some recognition (FGC).

Also arising from the discussion was the concept of intellectual bullying where the higher status individual would be seemingly or even openly dismissive of an idea, whilst later developing or extending it. For example in FGA:

$[\ldots]$ a $\mathrm{PhD}$ student, wouldn't be as quick in publishing [...] and somebody pinched his idea and published it. [...] there is a risk (FGA).

A similar view was expressed by some participants in FGB, who again confirm the notion of $\mathrm{KL}$ of intellectual property, resulting from KS. However, not all in FGB shared this view and were even dubious that KL could occur within an academic environment as it was perceived that trust is quite an essential component for promotion and growth of knowledge. For example, participants in FGB believed:

[...] when you go to an international conference I don't think anybody is thinking well I'm not going to say this because it is possible someone is going to steal it, because otherwise what's the point to go to the conference. If you're not going to transmit your findings or your main ideas what's the point? (FGB).

Nonetheless, this demonstrates the necessity of trust within $\mathrm{HE}$ as well as the need for academics to feel "secure" at which point of their research to share knowledge.

The opposite of KL sometimes occur when practice is not shared, and knowledge becomes sticky. This challenges the fluidity of the communication networks within the organisation, with newly developed knowledge being difficult to circulate beyond the originating community. Either situation, of KL or stickiness, can open the institution to a number of vulnerabilities, or opportunities which need to be identified and mitigated or exploited. In FGB, participants believe that there was a problem with sticky knowledge as there were no real outlets internally to disseminate knowledge, as quite often the research activities did not correspond with the teaching agenda. This can be further exacerbated by an absence of seminars, workshops and research groups which also contributed to shortfall.

This included the possibility of developing tunnel vision, where the individual becomes so engrossed in the process and as a result fails to see outside of their limited perception of the activity. This was succinctly expressed in FGA:

$[\ldots]$ there is also the risk of not sharing [...] which is that this idea is never going to be developed. You've got parts of it, but you're bringing someone else in because you feel that they can complement it (FGA).

The drive to achieve academic excellence is relentless, consequently, this opens up a number of vulnerabilities when individuals have to share and transfer knowledge. Indeed, KS both externally and internally present their benefits and challenges. However, despite the obvious areas of threats and vulnerabilities, some academics believe that such risks were worth taking.

\section{Discussion of findings}

$\mathrm{KS}$ in $\mathrm{HE}$ leads to increase competitiveness and responsiveness to commercial or academic opportunities, as collective knowledge leads to sustainability, innovation and creativity. KS is critical for institutions which are competing for the same grants, contracts, ranking
Academics' perception of knowledge sharing

1011 
IJEM

32,6

1012

positions, ratings on student experiences, amongst others. Even though much knowledge is embedded in different departments and individual academic staff, the existence of such structures often results in these entities operating as separate bodies, thus creating knowledge silos (Maponya, 2005). However, to be successful, academics are encouraged to embrace KS. Hence, individuals, departments, faculties and schools can no longer operate in isolation but are adopting more collaborative, team-based structures - with emphasis on the performance (Maponya, 2005). Increasingly, communication, cooperation and collaboration are considered essential not only to transfer existing knowledge but for the development of new knowledge. This is evident from the emphasis placed by major funding bodies for cross-disciplinary collaborations.

Although academic discourses have promoted the concept of KS and highlighted the benefits, members in the academic community remain cautious due to the risks of this sharing. This is owing to the competitive nature of the work environment in which individual academics are placed. Therefore, a lack of trust inhibits the open flow of communication and $\mathrm{KS}$ in general, as trust requires vulnerability and the willingness to be open to risks (Abrams et al., 2003). A lack of trust is often based on misunderstandings between parties as well as a lack of consistency between words and actions. Since any form of KS must be facilitated by trust, participants need to develop the confidence that their colleagues are not only competent but transparent with their knowledge. However, despite the apparent benefits of KS, owing to inequalities in status and perceived lack of job security, competition for the same scarce resources, knowledge hoarding rather than sharing is often seen as the path to recognition and career progression (Probst et al., 2000; Tiwana, 2002).

$\mathrm{KS}$ in $\mathrm{HE}$ institutions occurs in a sporadic even dialectical manner, where the outcome, whether risk or opportunity, is determined by the knowledge sharer and receiver. Nevertheless, since knowledge is not only generative but dynamic, KS is imperative for the emergence, continuation and advancement of knowledge itself and knowledge-intensive institutions. Therefore, such factors which prevented or promoted KS in the HE institutions were highlighted in the findings and were heavily dependent on the organisation structure, culture and political environment. For two of these institutions, research was heavily promoted; hence, the socio-political culture of these institutions, to some extent, encourages KS via internal processes such as seminars and research groups. On the other hand, one of these institutions was a point of critical juncture. Hence, KS was arbitrary. Consequently, individuals were left to develop interpersonal relationships and collaborative communication via processes such as research groups or communities of practice. In this case, the structure and culture did not support KS even though the political environment was changing. Hence, the decision to share knowledge is not just dependent on trust or perceived benefits but on the organisational culture (Swift and Hwang, 2013), individual experiences, trust and associated risks. In a collaborative and cooperative setting, where knowledge is shared openly and there is an exchange of useful ideas, trust becomes important. Conversely, in a competitive environment where knowledge is power and recognition and promotion can be affected, individuals are more likely to hoard knowledge.

Since universities not only generate new knowledge but also facilitate the exchange of existing knowledge, understanding this dynamics of interactions and managing the associated risks is not just crucial for creativity but even continuity. Consequently, risks such as KL, competition, knowledge stickiness and opportunities such as collaboration, recognition and proximity are the main result of $\mathrm{KS}$ in $\mathrm{HE}$. By applying a proactive risk management approach, one should consider the consequences, impact and frequency of the occurrences of the risk or opportunity. Even though some risks may have high impact, for example, theft or loss of intellectual property, the frequency of their occurrence is rare and therefore is considered worth taking. Again this outcome is similar in cases where the frequency is high and the impact is low. It can also be seen that the number of perceived 
risks also outnumbered the opportunities. Nonetheless, the effect of these opportunities on the institution and the individual is often seen as high. Indeed, the nature of the risks, its impact and the recipient need to be carefully considered when sharing knowledge across networks, communities and groups. Since qualitative risks identification is highly subjective and complex, the risks factors identified in this typology are not exhaustive but essential factors to be considered when determining and managing KS risks.
Academics' perception of knowledge sharing

\section{Conclusions}

To effectively accumulate knowledge, modern organisations must disseminate and share ideas, findings, interpretations and conclusions. This is particularly true in academic organisations, which have the dissemination of knowledge as their principal mission (teaching, conferences, research papers, monographs, etc.). Universities and research institutes aim at the development and dissemination of knowledge amongst their peers and society in general. In fact, like any other knowledge-intensive organisation, the university's competitive advantage lies in its ability to generate, disseminate and share knowledge as well as to prevent the loss of knowledge across the organisation's boundaries. Nonetheless, sharing of knowledge is based explicitly on trust, but sharing poses a number of risks and paradoxical opportunities. However, pressure to publish and disseminate early research results may lead to research ideas being adopted by others and even published first in more definite and prestigious terms, with greater recognition. On the other hand, fear of publishing early may lead to lack of peer support, scrutiny and critique which would otherwise be offered through the peer review process. Hence, academics find themselves in a precarious position of balancing what and when to share certain aspects of their knowledge.

Consequently, creating an atmosphere of trust, where the perception of risk and KL is diminished is necessary for effective KS. However, KS may be problematic in HE institutions since it involves different relationships and participation from academics at various stages in the careers and background may have conflicting interests. Indeed the willingness to share knowledge with others will increase when they believe that it will strengthen the ties, expand the scope of their association, as well as promote cooperation and collaboration for future work.

Therefore, what is essential for successful KS is a shared and agreed understanding of the risks. Being aware of the risks allows participants to make informed and calculated decisions, which not only protect the knowledge sharer but secure the continued propagation of knowledge. Further research should be conducted by examining how organisational culture impacts academics' behaviour and attitudes towards KS. It will also be useful to investigate the role of cultural characteristics in facilitating KS in HE. However, having a positive culture alone may be insufficient to facilitate KS. Therefore, further research should be conducted on the impact of aligning existing working KS practices with $\mathrm{HE}$ institutions goals.

\section{References}

Abrams, L.C., Cross, R., Lesser, E. and Levin, D.Z. (2003), "Nurturing interpersonal trust in knowledgesharing networks", The Academv of Management Executive, Vol. 17 No. 4, pp. 64-77.

Alberts, C.J. and Dorofee, A.J. (2010), Risk Management Framework, Carnegie Mellon University and Software Engineering Institute, Pittsburgh, PA, 1 August, available at: www.sei.cmu.edu

Al-Busaidi, K.A. and Olfman, L. (2017), "Knowledge sharing through inter-organizational knowledge sharing systems", VINE Journal of Information and Knowledge Management Sustems, Vol. 4 No. 1, pp. 110-136.

Alvesson, M. (1995), Management of Knowledge-Intensive Companies, Walter de Gruyter, Berlin. 
IJEM 32,6

Aminbeidokhti, A., Jamshidi, L. and Mohammadi Hoseini, A. (2016), "The effect of the total quality management on organizational innovation in higher education mediated by organizational learning", Studies in Higher Education, Vol. 41 No. 7, pp. 1153-1166.

Baier, A. (1986), "Trust and antitrust”, Ethics, Vol. 96 No. 2, pp. 231-260.

Barker, R. (2015), "Management of knowledge creation and sharing to create virtual knowledgesharing communities: a tracking study", Journal of Knowledge Management, Vol. 19 No. 2, pp. 334-350.

Bryman, A. (2015), Social Research Methods, Oxford University Press.

Cabrera, Á. and Cabrera, E.F. (2002), "Knowledge-sharing dilemmas", Organization Studies, Vol. 23 No. 5 , pp. 687-710.

Charmaz, K. (2010), Constructing Grounded Theory, Sage, London.

Chua, A. (2003), "Knowledge sharing: a game people play", Aslib Proceedings, Vol. 55 No. 3, pp. 117-129.

Connelly, C.E., Zweig, D., Webster, J. and Trougakos, J.P. (2011), "Knowledge hiding in organizations", Iournal of Organizational Behavior, Vol. 33 No. 1, pp. 64-88.

Cranfield, D.J. and Taylor, J. (2008), "Knowledge management and higher education: a UK case study", The Electronic Journal of Knowledge Management, Vol. 6 No. 2, pp. 85-100.

Denzin, N. and Lincoln, Y. (1994), The Handbook of Qualitative Research, Sage Publications, Thousand Oaks, CA.

Ford, D.P. and Staples, S. (2010), “Are full and partial knowledge sharing the same?", Lournal of Knowledge Management, Vol. 14 No. 3, pp. 394-409.

Forkosh-Baruch, A. and Hershkovitz, A. (2012), "A case study of Israeli higher-education institutes sharing scholarly information with the community via social networks", The Internet and Higher Education, Vol. 15 No. 1, pp. 58-68.

Fullwood, R., Rowley, J. and Delbridge, R. (2013), "Knowledge sharing amongst academics in UK universities", Journal of Knowledge Management, Vol. 17 No. 1, pp. 123-136.

Ghobadi, S. and Mathiassen, L. (2016), "Risks to effective knowledge sharing in agile software teams: a model for assessing and mitigating risks", Information Sustems Journal, Vol. 26 No. 2, pp. 95-125.

Holste, J.S. and Fields, D. (2010), "Trust and tacit knowledge sharing and use", Lournal of Knowledge Management, Vol. 14 No. 1, pp. 128-140.

Howell, K.E. (2013), An Introduction to the Philosophy of Methodology, Sage Publications, Thousand Oaks, CA.

Hsu, M.H. and Chang, C.M. (2014), "Examining interpersonal trust as a facilitator and uncertainty as an inhibitor of intra-organisational knowledge sharing", Information Sustems Journal, Vol. 24 No. 2 , pp. 119-142.

Ipe, M. (2003), "Knowledge sharing in organizations: a conceptual framework", Human Resource Development Review, Vol. 2 No. 4, pp. 337-359.

Kliem, R.L. (2000), "Risk management for business process reengineering projects", Information svstems Management, Vol. 17 No. 4, pp. 71-73.

Kliem, R.L. and Ludin, I.S. (2000), Reducing Project Risk, Gower, Hampshire.

Krueger, R.A. and Casey, M.A. (2000), Focus Groups: A Practical Guide for Applied Research, Sage Publications, London.

Li, X., Roberts, J., Yan, Y. and Tan, H. (2014), "Knowledge sharing in China-UK higher education alliances", International Business Review, Vol. 23 No. 2, pp. 343-355.

Loebbecke, C., van Fenema, P.C. and Powell, P. (2016), "Managing inter-organizational knowledge sharing", The Iournal of Strategic Information Sustems, Vol. 25 No. 1, pp. 4-14.

Maponya, P.M. (2005), "Fostering the culture of knowledge sharing in higher education", South African Journal of Higher Education, Vol. 19 No. 5, pp. 900-911. 
Matzler, K., Renzl, B., Müller, J., Herting, S. and Mooradian, T.A. (2008), "Personality traits and knowledge sharing", Journal of Economic Psychology, Vol. 29 No. 3, pp. 301-313.

Morgan, D.L. (1997), Focus Groups as Qualitative Research, Sage Publications, London.

Morgan, D.L. and Kreuger, R.A. (1993), When to use focus groups and why in Morgan DL (Ed.) Successful Focus Groups.

Nahapiet, J. and Ghoshal, S. (1998), "Social capital, intellectual capital, and the organizational advantage", Academv of Management Review, Vol. 23 No. 2, pp. 242-266.

Probst, G., Romhardt, K. and Raub, S. (2000), Managing Knowledge: Building Blocks for Success, J. Wiley.

Remedios, R. and Boreham, N. (2007), "Organisational learning and employees' intrinsic motivation", Journal of Education and Work, Vol. 17 No. 2, pp. 219-235.

Rowley, J. (2000), "Is higher education ready for knowledge management?", International Iournal of Educational Management, Vol. 14 No. 7, pp. 325-333.

Sadiq Sohail, M. and Daud, S. (2009), "Knowledge sharing in higher education institutions: perspectives from Malaysia", VINE Iournal of Information and Knowledge Management Sustems, Vol. 39 No. 2, pp. 125-142.

Schoorman, F.D., Mayer, R.C. and Davis, J.H. (2007), “An integrative model of organizational trust: past, present, and future", Academv of Management Review, Vol. 32 No. 2, pp. 344-354.

Smithson, J. (2000), "Using and analysing focus groups: limitations and possibilities", Journal of Social Research Methodology, Vol. 3 No. 2, pp. 103-119.

Swift, P.E. and Hwang, A. (2013), "The impact of affective and cognitive trust on knowledge sharing and organizational learning", The Learning Organization, Vol. 20 No. 1, pp. 20-37.

Syysnummi, P. and Laihonen, H. (2014), "Top management's perception of knowledge management in a vocational education and training organization in Finland", International Iournal of Educational Management, Vol. 28 No. 1, pp. 53-65.

Tedlock, B. (2000), "Ethnography and ethnographic representation", in Denzin, N. and Lincoln, Y. (Eds), The Handbook of Qualitative Research, Sage Publications, Thousand Oaks, CA, pp. 455-486.

Tiwana, A. (2002), The Knowledge Management Toolkit: Orchestrating IT, Strategy, and Knowledge Platforms, Pearson Education India.

Trivella, L. and Dimitrios, N.K. (2015), "Knowledge management strategy within the higher education", The Case of Greece, Vol. 175, pp. 488-495.

Trkman, P. and Desouza, K.C. (2011), "Knowledge risks in organisational networks: an exploratory framework", Lournal of Strategic Information Sustems, Vol. 21 No. 1, pp. 1-17.

Williams, J.B. and Jacobs, J.S. (2004), "Exploring the use of blogs as learning spaces in the higher education sector", Australasian Journal of Educational Technology, Vol. 20 No. 2, pp. 232-247.

Wong, E.S. (2008), "Explication of tacit knowledge in higher education institutional research through the criteria of professional practice action research approach: a focus group case study at an Australian University", International Journal of Doctoral Studies, Vol. 3.

\section{Corresponding author}

Fenio Annansingh can be contacted at: fannansinghjamieson@york.cuny.edu

For instructions on how to order reprints of this article, please visit our website:

www.emeraldgrouppublishing.com/licensing/reprints.htm

Or contact us for further details: permissions@emeraldinsight.com 